\title{
Design Windows and Cost Analysis on Helical Reactor
}

\author{
Y. Kozaki, S. Imagawa, A. Sagara \\ National Institute for Fusion Science, Toki, Japan \\ e-mail: kozaki.yasuji@nifs.ac.jp
}

\begin{abstract}
Based on the recent experiment results of LHD and the magnet technology-cost basis developed for ITER construction, the design window of helical reactors are analyzed. For searching design windows and investigating their economical potential, we have developed a mass-cost estimating model linked with system design code (HeliCos). We found that the LHD-type helical reactor has the technically and economically attractive design windows, where the major radius is increased as large as for the sufficient blanket space, but the magnetic stored energy is decreased to reasonable level because of lower magnetic field with the convenient physics basis of $\mathrm{H}$ factor near 1.1 to the ISS04 scaling and beta value of 5\%.
\end{abstract}

\section{Introduction}

In the long history of fusion reactor design studies many integrating system design codes had been developed and guided design studies, such as Generomak (J. Shefield1986) and system design codes in ARIES design studies. Most of the previous studies showed the importance of the mass power density, and suggested the directions to the much higher beta and the higher neutron wall loads. But as far as magnetic confinement fusion the direction for the compact reactor has become suffer from severe neutron wall loads, diverter heat loads, and tritium beading ratios. For practical fusion power plants, we should consider adequate size and mass power density.

To remove those misunderstandings on the necessity of compactness, we must investigate design windows with estimating the detail mass-cost relationships, especially on magnets and blankets. We have much experience on costs of fusion device through preparing ITER construction. Now we can discuss the costs of magnet and major facility with some reality with the ITER database. Helical reactors of an LHD-type are characterized by a pair of helical coils with large major radius but with moderate aspect ratio, which give us different approaches for power plants from tokamak reactors.

\section{The HeliCos code for system design and estimating cost}

\subsection{Major design parameters and their relationships}

The major relationships between plasma parameters and reactor parameters in the HeliCos code are identified as follows.

1) Basic geometry of plasma and helical coils

The geometry of plasma and helical coils are similar to LHD, i.e. polarity $1=2$, field periods $\mathrm{m}=10$, coil pitch parameter $\gamma=(\mathrm{m} / \mathrm{l}) /\left(\mathrm{R}_{\mathrm{c}} / \mathrm{a}_{\mathrm{c}}\right)=1.15 \sim 1.25$. We consider $\mathrm{a}_{\mathrm{p}}, \mathrm{a}_{\mathrm{c}}$ (minor radius of plasma and coil) and $\mathrm{a}_{\text {pin }}$ (inner minimum plasma radius) are also similar to LHD inward shift plasma case. The plasma radius $a_{p}$ is given by the LCFS (Last closed flux surface) of the LHD magnetic field calculations depending on $\gamma$. The larger plasma volume and the better plasma confinement conditions are discussed in the LHD inward shift cases. We should consider making the largest plasma volume given by optimizing the LCFS conditions, also with making the ergodic layer thin as possible. 
We can describe the relationships between $\mathrm{a}_{\mathrm{p}}$ and $\mathrm{a}_{\mathrm{c}}$, or $\mathrm{R}_{\mathrm{p}}$, as an equation of a linear regression and also an index regression only depending on $\gamma$, in the $\gamma=1.15 \sim 1.25$, based on LHD experiment.

$$
\begin{aligned}
& a_{p}=a_{c}(-1.3577+1.603 \times \gamma) \\
& a_{p}=0.2904 \times \gamma^{3.495} a_{c}=0.06292 \times \gamma^{3.495} R_{p}
\end{aligned}
$$

The plasma volume $V_{p}$ is expressed by the $R_{p}$ and $\gamma$.

$$
\mathrm{V}_{\mathrm{p}}=2 \pi^{2} \mathrm{a}_{\mathrm{p}}^{2} \mathrm{R}_{\mathrm{p}}=0.0841 \times \mathrm{R}_{\mathrm{p}}^{3} \gamma^{8.87}
$$

2) The space for blanket: $\Delta d$

The $\Delta \mathrm{d}$ is described with the configuration of plasma and helical coils as follows (Fig. 1),

$$
\begin{aligned}
& \Delta \mathrm{d}=\mathrm{a}_{\mathrm{c}}-\left(\mathrm{R}_{\mathrm{c}}-\mathrm{R}_{\mathrm{p}}\right)-\mathrm{a}_{\text {pin }}-\mathrm{H} / 2-\Delta \mathrm{t} \\
& \mathrm{a}_{\mathrm{pin}}=(-1.2479+1.2524 \gamma) \times\left(\mathrm{R}_{\mathrm{c}} / 3.9\right) \\
& \mathrm{H}=\left(\mathrm{I}_{\mathrm{HC}} /(\mathrm{j} \times \mathrm{W} / \mathrm{H})\right)^{0.5} \\
& \mathrm{I}_{\mathrm{HC}}=\mathrm{R}_{\mathrm{P}} \mathrm{B}_{0} /(2 \mathrm{~m}) \times 10 \\
& \mathrm{I}_{\mathrm{HC}}, \mathrm{j} \text { : helical coil current and current density, } \\
& \mathrm{H}, \mathrm{W} \text { : height and width of helical coils, } \\
& \Delta \mathrm{t} \text { : thermal insulation space. }
\end{aligned}
$$

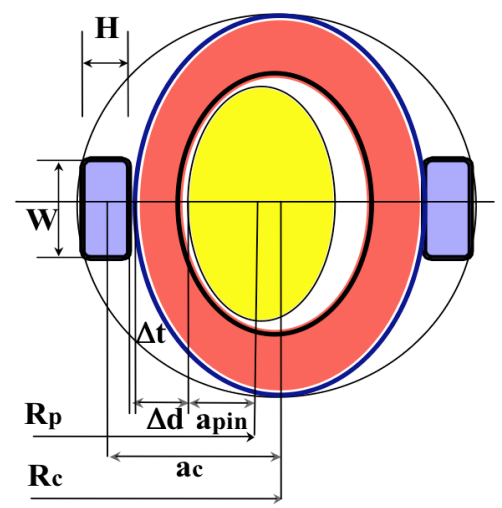

FIG.1 The profile of plasma, helical coil and blanket. The required $\Delta d$ gives the minimum $R_{p}$

The current density $\mathrm{j}$ depends on the $\mathrm{B}_{\max }$, which is given by the ratio of $\mathrm{B}_{\max } / \mathrm{B}_{0}$,

$$
\mathrm{B}_{\max } / \mathrm{B}_{0}=\left(0.4819+0.41847\left(\mathrm{a}_{\mathrm{c}} / \mathrm{H}\right)+0.0066851\left(\mathrm{a}_{\mathrm{c}} / \mathrm{H}\right)^{2}\right) \times\left(\mathrm{R}_{\mathrm{p}} / \mathrm{R}_{\mathrm{c}}\right)
$$

The minimum blanket space $\Delta \mathrm{d}$ depends not only on the blanket-shield design but also the ergodic layer depth, of which optimization is one of the most important issues.

2) Fusion power given with $B_{0}, \beta$, and $V_{P}$

The fusion power is calculated by the volume integration of fusion power density $\mathrm{p}_{\mathrm{f}}$ using the following reaction rate $\langle\sigma \mathrm{VV}\rangle_{\mathrm{DT}}$ and the plasma profile assumptions in the HeliCos code.

$$
\begin{aligned}
& \mathrm{p}_{\mathrm{f}}=\mathrm{n}_{\mathrm{T}} \mathrm{n}_{\mathrm{D}}<\sigma \mathrm{\sigma V}>_{\mathrm{DT}} \mathrm{V}_{\mathrm{p}} \times 17.58(\mathrm{MeV}) \times 1.6021 \times 10^{-19}(\mathrm{~J} / \mathrm{eV}) \times 10^{-3} \quad[\mathrm{GW}] \\
& <\sigma \mathrm{\sigma V}>_{\mathrm{DT}}=0.97397 \times 10^{-22} \times \exp \left\{0.038245(\ln (\mathrm{Ti}))^{3}-1.0074(\ln (\mathrm{Ti}))^{2}+6.3997 \ln (\mathrm{Ti})-9.75\right\}\left(\mathrm{m}^{3} / \mathrm{s}\right)
\end{aligned}
$$

We might use a simple parabolic profile, index $\mathrm{a}_{\mathrm{n}}$ for plasma density, and $\mathrm{a}_{\mathrm{T}}$ for temperature to consider peaking factors.

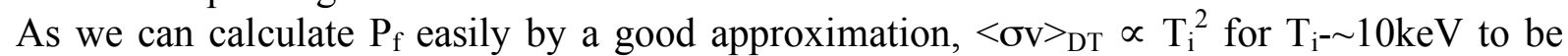
well known, we use a following equation for sensitivity studies.

$$
\mathrm{P}_{\mathrm{f}}=0.06272 /\left(1+2 \mathrm{a}_{\mathrm{n}}+2 \mathrm{a}_{\mathrm{T}}\right) \times \mathrm{n}_{\mathrm{e}}(0)^{2} \mathrm{~T}_{\mathrm{i}}(0)^{2} \mathrm{~V}_{\mathrm{p}} \times 10^{-6} \propto \beta^{2} \mathrm{~B}_{0}^{4} \mathrm{~V}_{\mathrm{P}}[\mathrm{GW}], \mathrm{n}_{\mathrm{e}}: 10^{19} / \mathrm{m}^{3}, \mathrm{~T}_{\mathrm{i}}: \mathrm{keV}
$$

3) Power balance with the energy confinement scaling ISS04 and $\mathrm{H}$ factor [1]

The power balance is described using the required energy confinement time $\tau_{\mathrm{Er}}$,

$$
\begin{aligned}
\mathrm{P}_{\alpha} \mathrm{f}_{\alpha}-\mathrm{R}_{\text {loss }}=\mathrm{W}_{\mathrm{p}} / \tau_{\mathrm{Er}} \quad\left(\mathrm{P}_{\alpha}=0.2 \mathrm{P}_{\mathrm{f}}, \quad \mathrm{f}_{\alpha}: \alpha \text { heating efficiency, } \mathrm{R}_{\text {loss }}:\right. \text { Radiation loss } \\
\left.\mathrm{W}_{\mathrm{p}}: \text { plasma stored energy, } \mathrm{W}_{\mathrm{p}} \propto \mathrm{n}_{\mathrm{e}}(0) \mathrm{T}_{\mathrm{i}}(0) \mathrm{V}_{\mathrm{p}}\right)
\end{aligned}
$$

We use the energy confinement scaling ISS04, which can be expressed only with the $\mathrm{R}_{\mathrm{p}}$ and $\gamma$ as geometrical parameters $\left(\mathrm{p}_{\mathrm{f}}=\mathrm{P}_{\mathrm{f}} / \mathrm{V}_{\mathrm{p}}, \mathrm{r}_{\text {loss }}=\mathrm{R}_{\text {loss }} /\left(0.2 \mathrm{f}_{\alpha} \mathrm{p}_{\mathrm{f}} \mathrm{V}_{\mathrm{P}}\right), \mathrm{r}_{\text {loss }}\right.$ : radiation loss rate $)$.

$$
\begin{aligned}
\tau_{\mathrm{E}}(\mathrm{ISS} 04) & =0.134\left(\mathrm{f}_{\alpha} \mathrm{P}_{\alpha}-\mathrm{R}_{\text {loss }}\right){ }^{-0.61} \mathrm{n}_{\mathrm{el}}{ }^{0.54} \mathrm{~B}_{0}{ }^{0.84} \mathrm{R}_{\mathrm{P}}^{0.64} \mathrm{a}_{\mathrm{p}}^{2.28}{ }^{2 / 3}{ }_{2 / 3}^{0.41} \\
& =6.23 \times 10^{-5} \mathrm{R}_{\mathrm{p}}^{1.09} \gamma^{2.98}\left(\mathrm{p}_{\mathrm{f}}\left(1-\mathrm{r}_{\text {loss }}\right)\right)^{-0.61} \mathrm{~B}_{0}^{0.84} \mathrm{n}_{\mathrm{el}}^{0.54} \quad[\mathrm{~ms}]
\end{aligned}
$$

The $\mathrm{H}$ factors are calculated using the density limit and density profile conditions as follows.

$$
\begin{aligned}
& \mathrm{H}_{\mathrm{f}}(\mathrm{ISS} 04)=\tau_{\mathrm{Er}} / \tau_{\mathrm{E}(\mathrm{ISS} 04)} \\
& \mathrm{H}_{\mathrm{f}}=76.4 \times \mathrm{f}_{\mathrm{np}} \times \mathrm{R}_{\mathrm{p}}^{-1.09} \gamma^{-2.98} \mathrm{p}_{\mathrm{f}}^{-0.16}(1-\alpha)^{-0.66} \mathrm{~B}_{0}{ }^{-1.11}
\end{aligned}
$$


$\mathrm{f}_{\mathrm{np}}$ :density profile effect coefficient $\left(\mathrm{f}_{\mathrm{np}}=1.0\right.$ in the $\mathrm{n}_{\mathrm{el}}=1.2 \mathrm{n}_{\mathrm{c} \text {. }}$ and $\mathrm{a}_{\mathrm{n}}=0.5$ case $)$ $\mathrm{n}_{\mathrm{c}}=149.0 \times \mathrm{p}_{\mathrm{f}}{ }^{1 / 2} \mathrm{~B}_{0}{ }^{1 / 2}\left[10^{19} / \mathrm{m}^{3}\right], \mathrm{n}_{\mathrm{c}}$ : Sudo density limit

\subsection{Design points given with the cross points of the three basic equations}

We can calculate the major design parameters, $\mathrm{B}_{0}, \mathrm{R}_{\mathrm{p}}, \gamma$, $\mathrm{P}_{\mathrm{f}}$, based on the three equations (1),(2),(3). Therefore the design points of the LHD-similar helical reactor are given with the cross points of the following three equations on the $B_{0}-R_{p}$ plane.

1) The function $\mathbf{B}_{\mathbf{0}}\left(\mathbf{R}_{\mathbf{p}}, \boldsymbol{\gamma}, \Delta \mathbf{d}, \mathbf{j}\right)$ from the $\Delta$ d-equation (1) $\mathrm{B}_{0}=\left(16 \mathrm{j} / \mathrm{R}_{\mathrm{p}}\right)\left((0.2633-0.1312 \gamma) \mathrm{R}_{\mathrm{p}}-20.41(\Delta \mathrm{d}+0.1)\right)^{2}[\mathrm{~T}](4)$

2) The function $\mathbf{B}_{0}\left(\mathbf{R}_{\mathbf{p}}, \boldsymbol{\gamma}, \boldsymbol{\beta}, \mathbf{P}_{\mathbf{f}}\right)$ from the $\mathrm{P}_{\mathrm{f}}$-equation (2)

$$
\mathrm{B}_{0}=92.64 \mathrm{P}_{\mathrm{f}}{ }^{1 / 4} \beta^{-1 / 2} \gamma^{-2.22} \mathrm{R}_{\mathrm{p}}^{-3 / 4} \quad[\mathrm{~T}]
$$

3) The function $\mathbf{B}_{\mathbf{0}}\left(\mathbf{R}_{\mathbf{p}}, \boldsymbol{\gamma}, \mathbf{H}_{\mathbf{f}}, \mathbf{P}_{\mathbf{f}}\right)$ from the $\mathrm{H}_{\mathrm{f}}$-equation (3)

Figure.2. shows a cross point of those three equations, with the common assumptions of $\gamma=1.2, \mathrm{Pf}=4 \mathrm{GW}, \mathrm{a}_{\mathrm{n}}=0.5$,

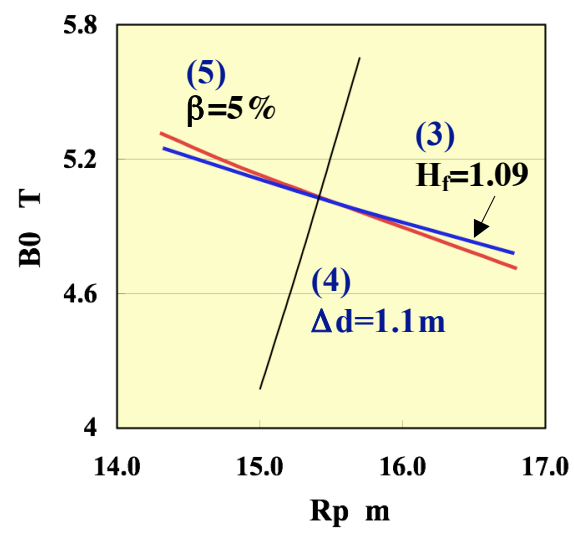

FIG.2 Design points given by the cross points of the three basic equations

$\mathrm{a}_{\mathrm{T}}=1, \mathrm{j}=26 \mathrm{~A} / \mathrm{mm}^{2}$, and with the constant key parameters in each equation, $\mathrm{H}_{\mathrm{f}}=1.09$ in (3), $\beta=5 \%$ in $(5)$ and $\Delta d=1.1 \mathrm{~m}$ in $(4)$, which are variable in other equation of course.

\section{Cost model}

\section{1. Magnet cost estimation}

Magnet costs hold the key essentially for magnetic confinement fusion to succeed in practical use. Although many uncertainties are remaining, we have already had much experience about large super conducting magnets. We estimated the unit cost to be related to weights and magnetic stored energy; thorough analyzing the cost factors of magnet systems based on the LHD construction, ITER construction and the FFHR-2m1 design studies [2]. In the FFHR2m1 design studies we considered a CIC conductors for helical coils based on the engineering base for ITER and the winding technology of LHD helical coils.

The cost factors are estimated in breakdown components such as super conducting strands, conduits, support structures, and winding process in each coil systems. The costs of the conductors and the winding occupy about $70 \%$ of the total magnet costs (FIG. 3 ).

$\square$ Strands $\quad$ C Conduit $\square$ Radial Plate

$\square$ Coil Case $\square$ Winding
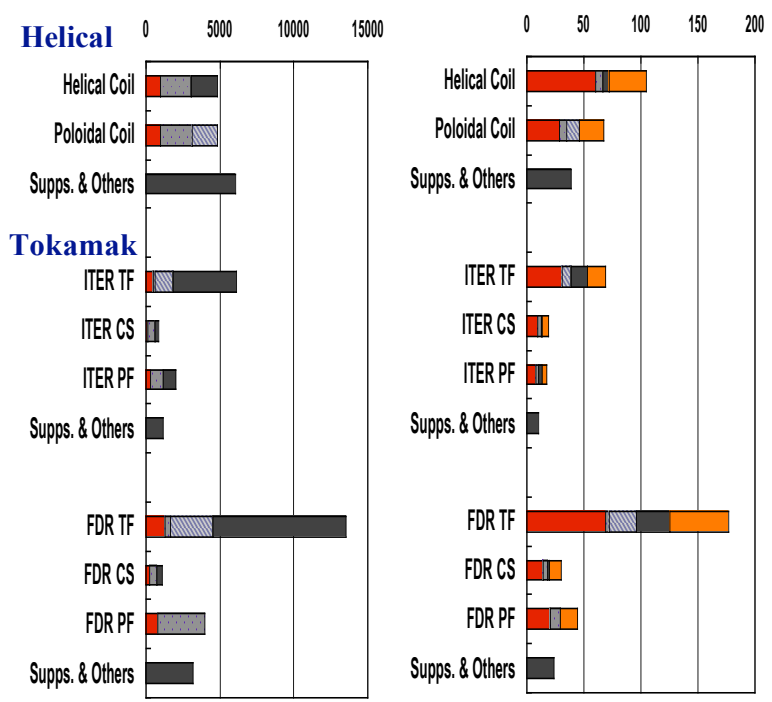

FIG.3. The weight and cost of the magnets of the helical reactor (FFHR-2m1) and the tokamak reactor(ITER). 
and FDR1999 report). For the superconducting magnets having similar configuration we could consider the costs are proportional to weights which are approximately proportional to the stored energy. In HeliCos code we can use the above unit cost per ton, that means the total unit cost is $1.59 \mathrm{BYen} / \mathrm{GJ}(14.4 \mathrm{M} \$ / \mathrm{GJ})$. Considering cost scaling and learning curve of superconducting magnets are the next interesting subject.

\section{2. Cost estimating methods}

The COE (Cost of Electricity) is calculated with the general cost estimating method and the unit cost data and scaling lows for BOP (balance of plant) [4,5]. The cost of magnets and blanket -shield are estimated based on mass cost analysis. The capital costs are calculated using rather low FCR ( 0.0578:Fixed chrge rate) used in the recent report of Japanese AEC for estimating nuclear power plants (40 years life time and $3 \%$ discount rate). In estimating fusion power plants the operation cost of magnet should be taken special care for the inherent characteristics of long lifetime and easy maintenance. In regard to blanket the periodic replacement is necessary, and the availability factors are estimated in changing with neutron wall loads.

\section{Basic characteristics of LHD-type helical reactor design window}

\subsection{Design windows limited by the constraints of blanket space and magnetic energy}

In general the design spaces of helical reactor are limited with following three conditions, 1) $\Delta d$ blanket space conditions necessary for tritium breading, 2) $B_{0}$ and $V_{P}$ conditions satisfying power balance with $\mathrm{H}$ factor limitation, 3) the upper magnetic stored energy (W) constraints for avoiding the difficulty of manufacturing. Then the design space on the $\mathrm{R}_{\mathrm{P}}-\mathrm{B}_{0}$ (or $\mathrm{W}$ ) plane has the minimum $\mathrm{R}_{\mathrm{P}}$ boundary given by the $\Delta \mathrm{d}$ constraints, the lower boundary of $\mathrm{B}_{0}$ from $\mathrm{H}$ factor conditions, and the upper boundary of $\mathrm{B}_{0}$ from the $\mathrm{W}$ constraints. With increasing $\gamma$ the design points of helical reactors move to the larger $R_{P}$ according to increasing plasma radius and much severe $\Delta d$ constraints. Though the minimum $R_{P}$ increases with the larger $\gamma$, the $\mathrm{B}_{0}$ decreases so much that the $\mathrm{W}$ also decreases.
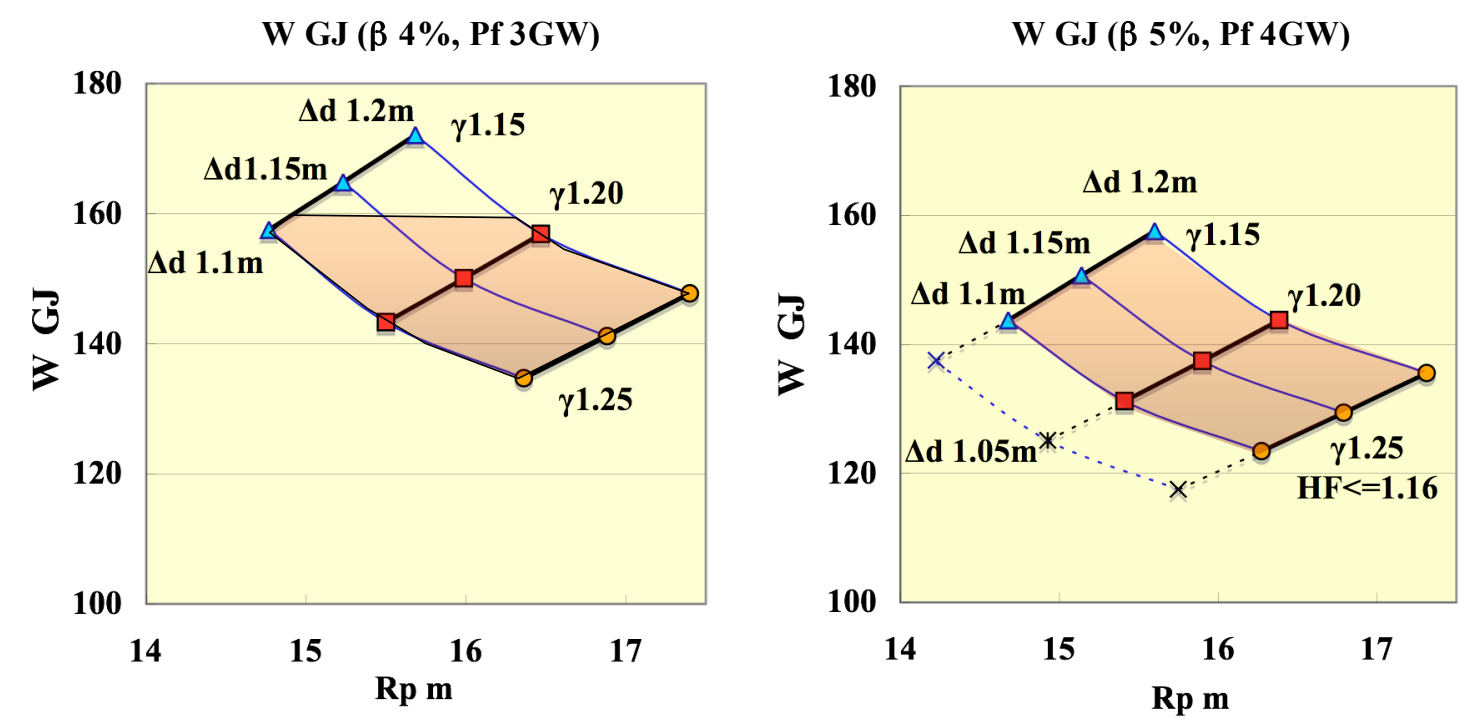

Fig. 4. The design windows limited with $\Delta d \geq 1.1 \mathrm{~m}, H_{f} \leq 1.16, W<160 \mathrm{GJ}$, depending on $\gamma$ and $\beta$. $H_{f}=1.16$ means the 1.2 times value achieved in LHD experiment [1]. $j=26 \mathrm{~A} / \mathrm{mm}^{2}$ is premised. 
Figure 4 shows the basic design windows with the constraints of $\Delta \mathrm{d}=1.10 \sim 1.20, \mathrm{H}_{\mathrm{f}}<1.16$, and $\mathrm{W}<160 \mathrm{GJ}$, in the cases of typical $\beta$-Pf assumptions. It is clear that the design windows of helical reactor change largely depending on $\gamma$ and $\beta$, but in regard to reactor size there are rather broad windows, $\mathrm{R}_{\mathrm{P}}=15 \mathrm{~m} \sim 17 \mathrm{~m}$ within acceptable $\mathrm{W}$.

\subsection{The helical reactor design windows depending on $\gamma$ and $\beta$}

Searching for attractive fusion power plants a wide range of design options are investigated, $\beta$ values from $3 \%$ to $5 \%$, and fusion power $\mathrm{P}_{\mathrm{f}}$ from $2 \mathrm{GW}$ to $4 \mathrm{GW}$ as shown in Fig.5.

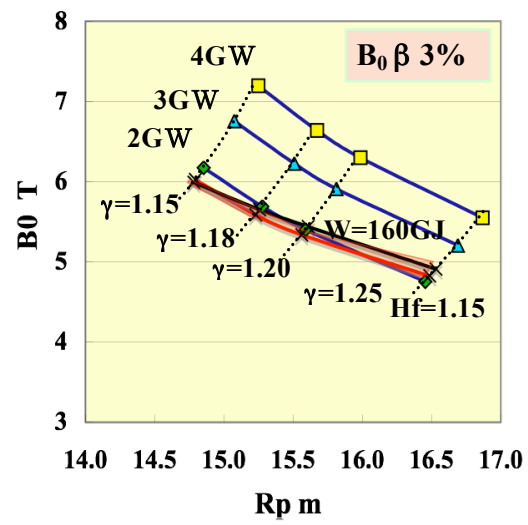

FIG.5 (1)a. $B_{0}$ in $\beta 3 \%$ case

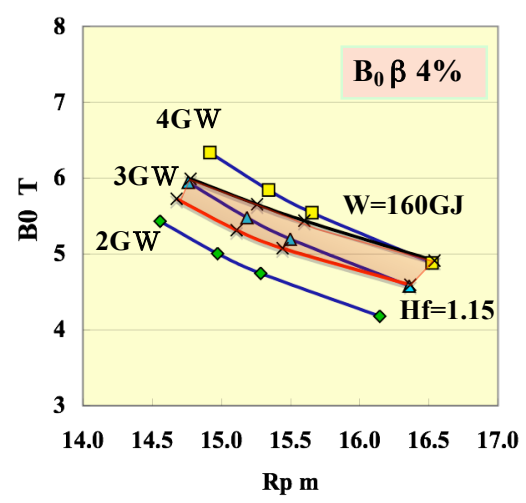

FIG.5 (2)a. Bo in $\beta 4 \%$ case

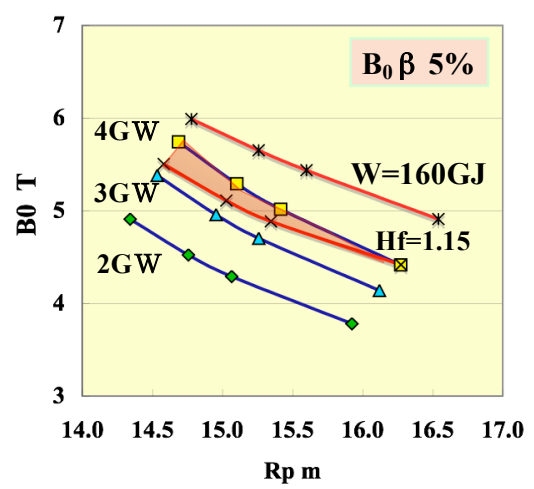

FIG.5 (3)a. Bo in $\beta 5 \%$ case

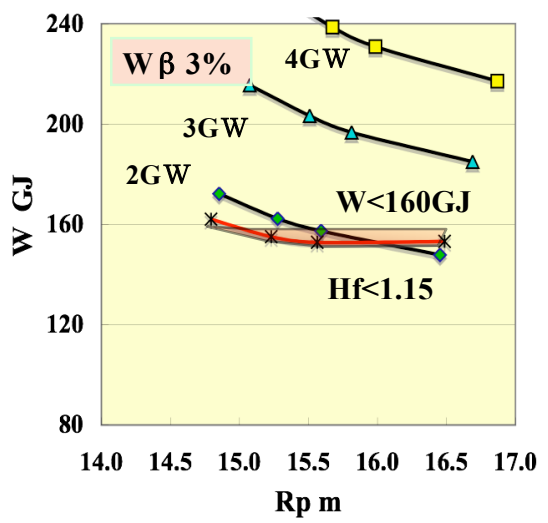

FIG. 5 (1)b. W in $\beta 3 \%$ case

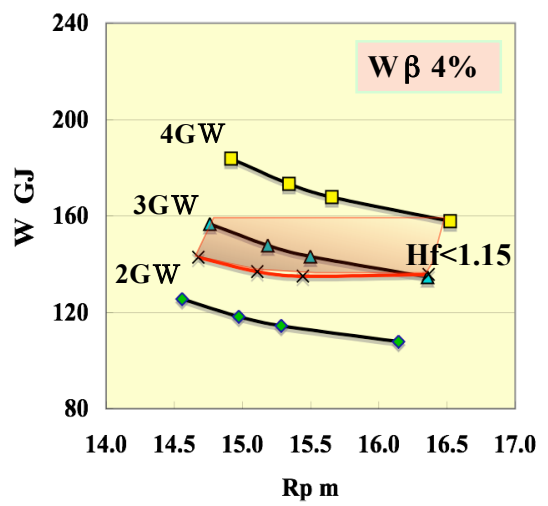

FIG.5 (2)b. W in $\beta$ 4\%case

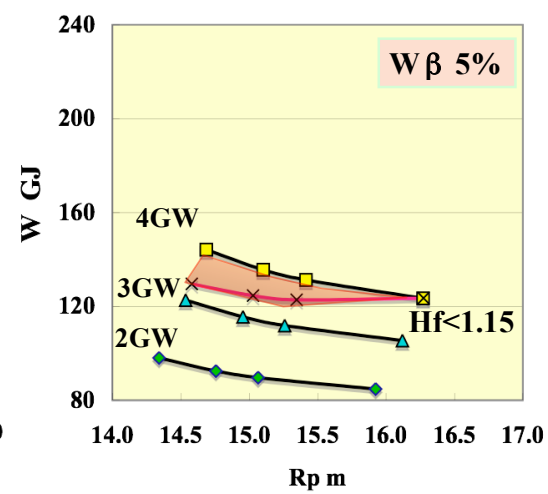

FIG.5 (3)b. W in $\beta 5 \%$ case

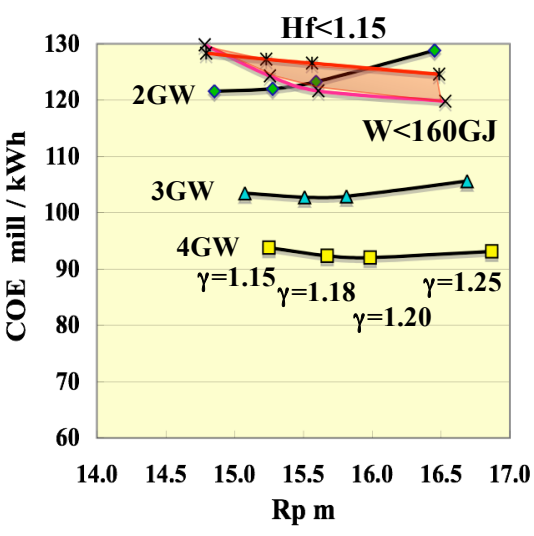

FIG.5 (1)c COE in $\beta 3 \%$

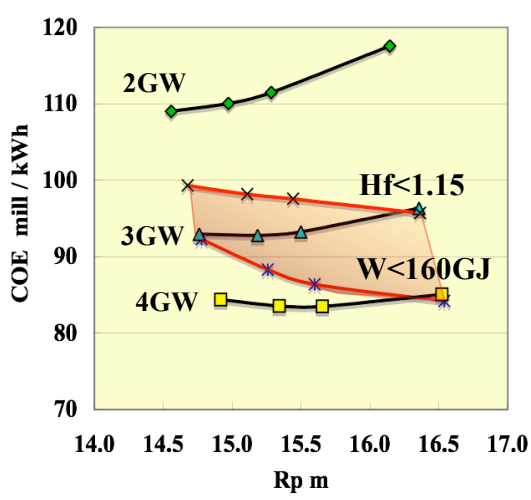

FIG.5 (2) C. COE in $\beta 4 \%$

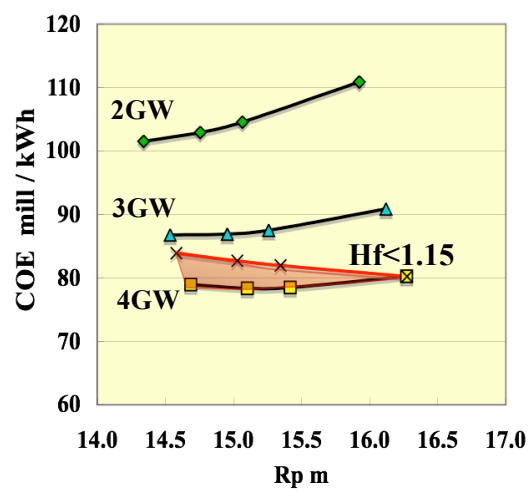

FIG.5 (3)c. COE in $\beta 5 \%$

FIG.5. The helical reactor design windows strongly depending on $\gamma$ and $\beta$, limited with the constraints of $\Delta d=1.1 \mathrm{~m}, H_{f} \leq 1.15, W<160 G J$. The $\gamma$ dependence are shown with the four points, $\gamma=1.15,1.18,1.20,1.25$ on each line. 
In the $\beta 3 \%$ cases, even though in the smaller $\mathrm{P}_{\mathrm{f}}$ plants, magnetic stored energy $\mathrm{W}$ is near upper boundary. In the $\beta 4 \%$ cases, we can consider wide design space with $\mathrm{B}_{0}=5 \sim 6 \mathrm{~T}$, $\mathrm{Pf}=3 \sim 4 \mathrm{GW}$, although $\mathrm{W}$ is rather large, $\sim 150 \mathrm{GJ}$.

In the $\beta 5 \%$ cases, we can consider the optimum design windows of $\mathrm{P}_{\mathrm{f}}=3.3 \sim 4 \mathrm{GW}$ plants with $\mathrm{R}_{\mathrm{P}}=14.6 \sim 16.3 \mathrm{~m}, \mathrm{~B}_{0}=4.4 \sim 5.5 \mathrm{~T}$, and $\mathrm{W}=125 \sim 140 \mathrm{GJ}$

We should notice that the $\mathrm{H}$ factor conditions in $\beta 5 \%$ are severe in the smaller $\mathrm{P}_{\mathrm{f}}$ case and the larger $\gamma$ case. Therefore in the $\mathrm{H}_{\mathrm{f}}=1.10$ case we must consider the minimum $\mathrm{Pf}$ is $3.8 \mathrm{GW}$ for $\gamma=1.15$, and Pf is $4.5 \mathrm{GW}$ for $\gamma=1.25$. We should also notice that the design windows must shift the larger $\mathrm{Rp}$ and the larger $\mathrm{W}$ in the large $\Delta \mathrm{d}$ case, as shown in Fig. 4. For examples, as results of increasing the thickness of ergodic layer $10 \mathrm{~cm}, \Delta \mathrm{d}$ increases from $1.1 \mathrm{~m}$ to $1.2 \mathrm{~m}$. As shown in Fig. 5., such large $\Delta \mathrm{d}$ case makes design points shift about $\sim 1 \mathrm{~m}$ to the larger Rp.

The COEs corresponding to each design window are also shown in Fig.5. In the $\beta 3 \%$ cases the COEs are very high because of the smaller Pf and the larger W. In the $\beta 4 \sim 5 \%$ cases, we can consider the broad design windows with the reasonable COE even though in the larger Rp cases. We should carefully consider the reasons why the remarkable results of the COE can be got in the rather large size reactor. In the next section we discuss in detail.

\section{Standard helical power plants and economic analysis}

\subsection{Standard helical reactors of $3 \sim 4 \mathrm{GW}$ fusion power}

Table 1. shows the major design parameters and costs of typical helical reactors. For 4GW fusion power plants $\beta=5 \%$ is expected for $4 \mathrm{GW}$ plants, but for $3 \mathrm{GW}$ plants the smaller $\beta$ $(\sim 4.4 \%)$ is yet manageable. With selecting adequate $\gamma$ we can consider the wide range of design parameters, $\mathrm{Rp}=14.7 \sim 16.3 \mathrm{~m}, \mathrm{~B}_{0}=4.2 \sim 5.7 \mathrm{~T}$, and $\mathrm{W}=122 \sim 144 \mathrm{GJ}$ with a varieties of $\gamma$. We could understand the reason why the difference of design parameters for different $\gamma$ is so large, by comparing plasma volume, i.e., $920 \mathrm{~m}^{3}$ in $\gamma 1.15$ versus $2600 \mathrm{~m}^{3}$ in $\gamma 1.25$. The sensitivity of increasing $V_{P}$ versus decreasing $B_{0}$ is very interesting. The optimization of the LCFS $\left(\mathrm{V}_{\mathrm{p}}\right)$ might be one of the most important issues.

The major parameters in Table 1. are dominated with the simple relationships shown in 2.2. But there are remaining many uncertainties regarding power flows and mass flows, especially in the local heat load to the diverter. Those problems on optimizing LCFS, controlling ergodic layer and diverter plasma must be critical issues to be considered in the next design studies.

\section{2 Economic characteristics of helical power plants}

We could consider the magnet cost and the blanket-shield cost are dominant cost factors in the magnetic confinement fusion reactor, as far as the normal steady operations are achieved with the reasonable recirculating power, and the sufficient plant availability factors without suffering from too high heat load or neutron load.

In the LHD-similar-shape helical reactors, with increasing $\mathrm{R}_{\mathrm{p}}$ and $\gamma$ (i.e., $\mathrm{a}_{\mathrm{p}}$ ) the $\mathrm{B}_{0}$ decreases much in the same $\beta-\mathrm{P}_{\mathrm{f}}$ and $\Delta \mathrm{d}$ conditions as shown in Fig 6 . That is why the magnetic stored energy $\mathrm{W}$ decreases even if in the larger coil size. These characteristics between plasma volume $\left(\mathrm{R}_{\mathrm{p}}, \gamma\right)$ and $\mathrm{B}_{0}$, and magnet cost are shown in Fig. 7. The costs of blanket and shield (Cbs) are estimated basing on FFHR-2m1 blanket design studies [2] and are increased in 
proportion with $\mathrm{R}_{\mathrm{p}} \mathrm{a}_{\mathrm{p}}$. The sensitivity analysis regarding current density, plasma profile and density limit are carried out.

Using the magnetic stored energy and the unit cost mentioned in Fig. 3., we estimated the magnet costs, which are $1800 \mathrm{M} \$(\gamma=1.25,15400$ ton) to $2080 \mathrm{M} \$(\gamma=1.15,18000$ ton $)$. Those magnet cost ratio to total plant cost are about $30 \%$.

TABLE 1: THE STANDARD HERICAL REACTORS OF 3 4 GW FUSION POWER.

\begin{tabular}{|c|c|c|c|c|c|}
\hline Design Parameters & Symbol (unit) & \multicolumn{3}{|c|}{$\begin{array}{l}\text { 4GW standard plants } \\
\beta=5 \%, \mathrm{Hf}=1.06-1.15\end{array}$} & $\begin{array}{c}\text { 3GW } \\
\mathrm{Hf}=1.15\end{array}$ \\
\hline Coil pitch parameter & $\gamma$ & 1.15 & 1.20 & 1.25 & 1.20 \\
\hline Coil major Radius & $\mathrm{R}_{\mathrm{c}}(\mathrm{m})$ & 15.91 & 16.70 & 17.63 & 16.69 \\
\hline Coil minor radius & $a_{c}(m)$ & 3.66 & 4.01 & 4.41 & 4.00 \\
\hline Plasma major radius & $\mathrm{R}_{\mathrm{p}}(\mathrm{m})$ & 14.69 & 15.42 & 16.27 & 15.40 \\
\hline Plasma radius & $a_{p}(m)$ & 1.78 & 2.27 & 2.85 & 2.27 \\
\hline Inner plasma radius & $a_{\text {pin }}(m)$ & 0.78 & 1.09 & 1.44 & 1.09 \\
\hline Plasma volume & $V_{p}\left(m^{3}\right)$ & 916 & 1565 & 2604 & 1561 \\
\hline Magnetic field & $\mathrm{B}_{0}(\mathrm{~T})$ & 5.74 & 5.02 & 4.42 & 5.00 \\
\hline Average beta & $\beta$ & 5.0 & 5.0 & 5.0 & 4.37 \\
\hline Fusion power & $\operatorname{Pf}(\mathrm{GW})$ & 4.00 & 4.00 & 4.00 & 3.00 \\
\hline Energy confinement time (ISS95) & $\tau_{\mathrm{E}(\mathrm{ISS} 95)}(\mathrm{msec})$ & 0.84 & 1.04 & 1.25 & 1.14 \\
\hline Energy confinement time ISS04 & $\tau_{\mathrm{E}(\mathrm{ISS} 04)}(\mathrm{msec})$ & 1.43 & 1.78 & 2.14 & 1.95 \\
\hline Required energy confinement time & $\tau_{\mathrm{Er}}(\mathrm{msec})^{*}$ & 1.53 & 1.95 & 2.47 & 2.24 \\
\hline $\mathrm{H}$ factor to ISS04 & Hf & 1.064 & 1.094 & 1.151 & 1.150 \\
\hline Radiation loss ** & Rloss (GW) & 0.13 & 0.12 & 0.11 & 0.09 \\
\hline Electron density & $\mathrm{n}_{\mathrm{e}}(0)\left(10^{19} / \mathrm{m}^{3}\right)$ & 36.06 & 25.77 & 18.75 & 22.31 \\
\hline Line average density & $\mathrm{n}_{\mathrm{el}}\left(10^{19} / \mathrm{m}^{3}\right)$ & 28.32 & 20.24 & 14.73 & 17.52 \\
\hline Density limit & $\mathrm{n}_{\mathrm{c}}\left(10^{19} / \mathrm{m}^{3}\right)$ & 23.6 & 16.87 & 12.27 & 14.61 \\
\hline Ion Temperature & $\operatorname{Ti}(0)$ & 14.68 & 15.67 & 16.69 & 15.69 \\
\hline Iota $2 / 3$ & $\mathrm{t}(2 / 3)$ & 0.904 & 0.775 & 0.641 & 0.775 \\
\hline Maximum field on coils & $\operatorname{Bmax}(\mathrm{T})$ & 12.16 & 11.91 & 11.78 & 11.88 \\
\hline Coil current & $\mathrm{I}_{\mathrm{HC}}(\mathrm{MA})$ & 42.18 & 38.67 & 35.93 & 38.50 \\
\hline Coil current density & $\mathrm{j}\left(\mathrm{A} / \mathrm{mm}^{2}\right)$ & 26.0 & 26.0 & 26.0 & 26.0 \\
\hline Helical Coil height & $\mathrm{H}(\mathrm{m})$ & 0.90 & 0.86 & 0.83 & 0.86 \\
\hline Blanket space & $\Delta \mathrm{d}(\mathrm{m})$ & 1.10 & 1.10 & 1.10 & 1.10 \\
\hline Neutron wall loads & $\mathrm{f}_{\mathrm{n}}\left(\mathrm{MW} / \mathrm{m}^{2}\right)$ & 2.9 & 2.2 & 1.7 & 1.7 \\
\hline Weight of Blanket and shield & Mbs (ton) & 8580 & 11360 & 14920 & 11340 \\
\hline Magnetic stored energy & $\mathrm{W}(\mathrm{GJ})$ & 144 & 131 & 123 & 130 \\
\hline Weight of magnets & Mmag (ton) & 18000 & 16400 & 15400 & 16200 \\
\hline Magnet $\operatorname{cost}(\%) * * *$ & Cmag & $2079(34.6)$ & $1893(31.0)$ & $1780(28.0)$ & $1875(33.7)$ \\
\hline Blanket and shield cost $(\%) * * *$ & Cbs $(M \$)$ & $889(14.8)$ & $1177(19.3)$ & $1546(24.3)$ & $1175(21.1)$ \\
\hline Total construction cost & $C$ (total) & 7270 & 7393 & 7705 & 6735 \\
\hline Net electric power & Pn (GW) & 1604 & 1601 & 1598 & 1194 \\
\hline Total auxiliary power & $\mathrm{Pa}(\mathrm{GW})$ & 109 & 112 & 115 & 91 \\
\hline Plant availability factor & $\mathrm{f}_{\mathrm{A}}$ & 0.680 & 0.706 & 0.726 & 0.727 \\
\hline Capital cost & $\mathrm{mill} / \mathrm{kWh}$ & 44.0 & 43.2 & 43.8 & 51.2 \\
\hline Operation cost & $\mathrm{mill} / \mathrm{kWh}$ & 26.8 & 27.1 & 28.2 & 31.4 \\
\hline Replacement cost & mill/kWh & 8.18 & 8.19 & 8.21 & 8.24 \\
\hline Fuel cost & mill/kWh & 0.023 & 0.022 & 0.021 & 0.021 \\
\hline COE(Cost of electricity) & $\mathrm{mill} / \mathrm{kWh}$ & 79.0 & 78.5 & 80.3 & 90.9 \\
\hline
\end{tabular}

$*$ Effective ion charge Zeff $=1.32, * *$ Alpha heating efficiency 0.9 , and profile index $\mathrm{a}_{\mathrm{n}}=0.5, \mathrm{a}_{\mathrm{T}}=1.0$.

*** The magnet costs, blanket and shield costs include the engineering indirect cost. 
When the $\mathrm{R}_{\mathrm{p}}$ and $\gamma$ increase, the magnet cost decreases but the blanket-shield cost increases. Therefore the COEs of helical reactors, depending on $R_{p}, \gamma$, show the bottom as the result of the trade-off between the magnet cost and the blanket-shield cost, i.e., $\mathrm{B}_{0}$ versus plasma volume.

The COEs of helical reactors shown in Fig. 7 suggest us that the technically and economically attractive design windows exist in the rather wide area of the large $R_{p}(15 \sim 16 \mathrm{~m})$, medium $\gamma$ $(\sim 1.20)$ and $\beta$ values $(\sim 5 \%)$, and the reasonable magnetic stored energy $(\sim 130 \mathrm{GJ})$.

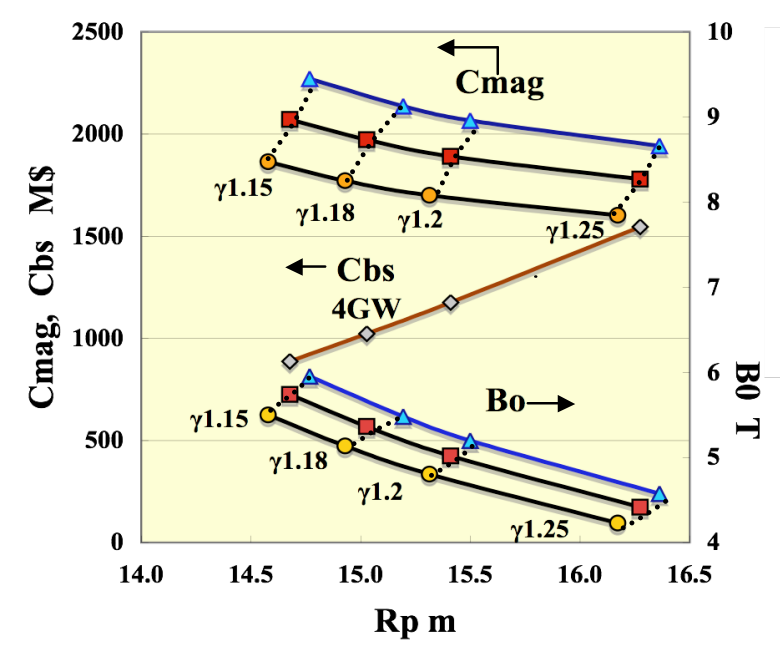

FIG. 6. The $B_{0}$, magnet cost (Cmag), and blanket Cost (Cbs) depend on $R_{p}, \gamma$ and $\beta$. When $R_{p}$ and $\gamma$ increase, Cmag decreases but Cbs increases. Those plots on $R_{p}(\gamma)$ are given with $\Delta d=1.1 \mathrm{~m}$.
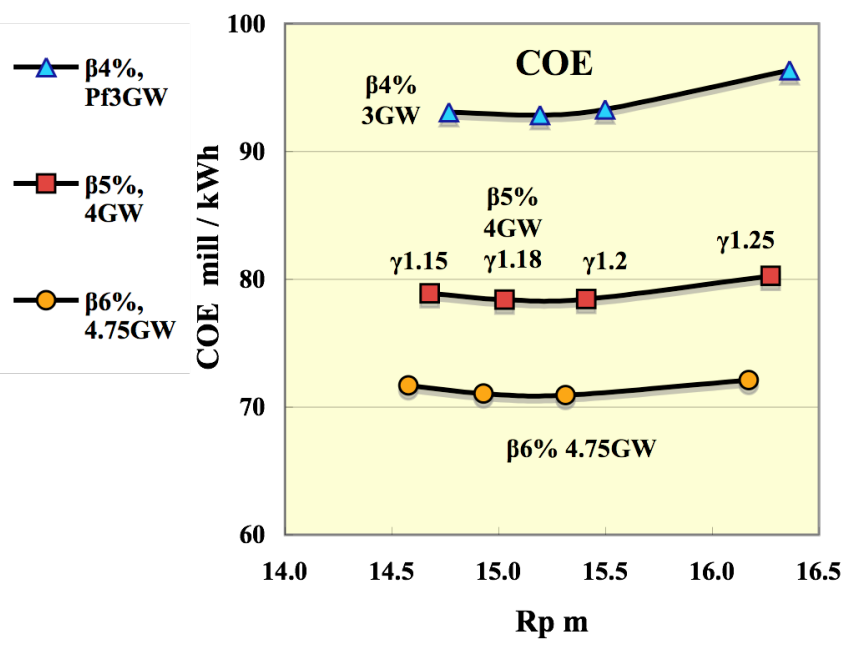

FIG. 7. The COEs of helical reactors, which depend on $R_{p}, \gamma$ and $\beta$, show the bottom as the result of the trade-off between the Cmag and Cbs, i.e., $B_{0}$ versus plasma volume.

\section{Conclusions}

We can summarize the results of analysis as follows,

1) LHD-type helical reactors have the attractive design windows in rather large plasma major radius of $15 \sim 16 \mathrm{~m}$, with the sufficient blanket space and the reasonable magnetic stored energy of $120 \sim 140 \mathrm{GJ}$ based on the physics basis of $\mathrm{H}$ factor near 1.1 and $\beta$ of $5 \%$.

2) The $\beta$ dependence is very important for selecting the optimum fusion power with reasonable magnetic energy, so that the confirming good confinement in the near $\beta \sim 5 \%$ plasma is the first priority of critical issues.

3) The $\gamma$ dependence is essential in Heliotron reactors that is critically sensitive not only for optimizing LCFS (plasma volume) but for selecting the optimum blanket design.

4) There are many remaining subject to be studied, in especially, the problem of the particle and heat loads on the diverter are a critical issue to be considered in the next analysis.

Finally it is significantly important for us to make the database reliable in technically and economically that can be used for realizing vision of a realistic road map for fusion energy.

\section{References}

[1] H. Yamada et al., Nuclear Fusion 45, 1684 (2005).

[2] A. Sagara et al., Nuclear Fusion 45, 258 (2005).

[3] S. Imagawa and A. Sagara, Plasma Science \& Technology 7, 2626 (2005).

[4] Y. Kozaki et al., Proc. Seventh Int. Conf. on Emerging Nuclear Energy Systems, 76 (1993)

[5] Y. Kozaki et al., 19th IAEA-CN-94/FTP1/25 (2002) 